\title{
EFFECT OF SERVICEABILITY LIMITS ON OPTIMAL DESIGN OF STEEL PORTAL FRAMES
}

Duoc T. Phan ${ }^{\mathrm{a}}$, James B.P. Lim ${ }^{\mathrm{a}^{*}}$, Tiku T. Tanyimboh ${ }^{\mathrm{b}}$, R. Mark Lawson ${ }^{\mathrm{c}}$, Yixiang Xu ${ }^{\mathrm{b}}$, Steven Martin $^{\mathrm{b}}$, Wei Sha ${ }^{\mathrm{a}}$

${ }^{a}$ School of Planning, Architecture and Civil Engineering, Queen's University Belfast, David Keir Building, Belfast, BT9 5AG, UK

${ }^{b}$ Department of Civil Engineering, University of Strathclyde, John Anderson Building, Glasgow, G4 $O N G, U K$

${ }^{c}$ Department of Civil Engineering, University of Surrey, Guildford SL5 7QN, UK

${ }^{*}$ Corresponding author

Duoc T. Phan: School of Planning, Architecture and Civil Engineering, David Keir Building, Queen's University, Belfast, BT9 5AG, UK. Email: tphan01@qub.ac.uk

James B.P. Lim: School of Planning, Architecture and Civil Engineering, David Keir Building, Queen's University, Belfast, BT9 5AG, UK. Email: j.lim@qub.ac.uk

Tiku T. Tanyimboh: Department of Civil Engineering, University of Strathclyde, 107 Rottenrow, Glasgow, G4 0NG, UK. Email: tiku.tanyimboth@strath.ac.uk

R. Mark Lawson: The Steel Construction Institute, Ascot, Berkshire, SL5 7QN, UK. Email: m.lawson@surrey .ac.uk

Yixiang Xu: Department of Civil Engineering, University of Strathclyde, 107 Rottenrow, Glasgow, G4 0NG, UK. Email: yixiang.xu@strath.ac.uk

Steven Martin: Department of Civil Engineering, University of Strathclyde, 107 Rottenrow, Glasgow, G4 0NG, UK. Email: steven.martin@strath.ac.uk

Wei Sha: School of Planning, Architecture and Civil Engineering, David Keir Building, Queen's University, Belfast, BT9 5AG, UK. Email:w.sha@qub.ac.uk

Duoc T. Phan: PhD student; James B.P. Lim: PhD, Lecturer; Tiku T. Tanyimboh: PhD, Senior Lecturer; R. Mark Lawson: PhD, Professor; Yixiang Xu: PhD, Lecturer; Steven Martin: PhD student; Wei Sha: PhD, Professor.

This article was published in the Journal of Constructional Steel Research, Volume 86, pp.74-84, 2013.

DOI: 10.1016/j.jcsr.2013.03.001

The final publication is available at: http://www.sciencedirect.com/science/article/pii/S0143974X13000710\# 


\title{
EFFECT OF SERVICEABILITY LIMITS ON OPTIMAL DESIGN OF STEEL PORTAL FRAMES
}

\begin{abstract}
The design of hot-rolled steel portal frames can be sensitive to serviceability deflection limits. In such cases, in order to reduce frame deflections, practitioners increase the size of the eaves haunch and / or the sizes of the steel sections used for the column and rafter members of the frame. This paper investigates the effect of such deflection limits using a real-coded niching genetic algorithm (RC-NGA) that optimizes frame weight, taking into account both ultimate as well as serviceability limit states. The results show the proposed GA is efficient and reliable. Two different sets of serviceability deflection limits are then considered: deflection limits recommended by the Steel Construction Institute (SCI), which is based on control of differential deflections, and other deflection limits based on suggestions by industry. Parametric studies are carried out on frames with spans ranging between $15 \mathrm{~m}$ to $50 \mathrm{~m}$ and column heights between $5 \mathrm{~m}$ to $10 \mathrm{~m}$. It is demonstrated that for a $50 \mathrm{~m}$ span frame, use of the SCI recommended deflection limits can lead to frame weights that are around twice as heavy as compared to designs without these limits.
\end{abstract}

Keywords: optimization, hot-rolled steel, portal frames, niching, real-coded GA, serviceability limits. 


\section{Introduction}

In the UK, it is estimated that $50 \%$ of the hot-rolled steel used in construction is fabricated into single-storey buildings, of which portal frames are the most popular form [1-2]. Practitioners generally design hot-rolled steel portal frames to the ultimate limit state using plastic design, in accordance with the British Standard BS 5950 [3]. However, whilst modern practice has shown that plastic design produces the most efficient designs in the majority of cases [1-2], elastic design is still used, particularly when serviceability limit state deflections will control frame design [4-5].

In general, serviceability limit state deflections for portal frames are not specified in the British Standards (as well as other National Standards), and the decision as to the appropriate limit on serviceability deflections is left to the judgement of the engineer. A typical explanation for this specific exclusion of deflection limits is that deflections of portal frames have no direct significance on the serviceability of the frame itself. Although this explanation is technically correct, excessive deflections will affect, among other things, the serviceability of the cladding, water-tightness and the visual acceptability of the building in general [4].

The Steel Construction Institute (SCI) has produced an Advisory Desk Note [6] in which deflection limits of steel portal frames are proposed [2,4]. These limits are intended to avoid problems of tearing in cladding fixings due to differential deflections. These deflection limits are shown in Table 1. The parameters used for the frame are defined in Fig. 1. However, for frames with single skin profiled metal cladding and without use of gantry cranes, it is generally regarded by steel fabricators that the SCI recommendations for deflection limits can be too conservative. However, the SCI limits are widely adopted for a wide range of cladding systems, such as builtup insulated roofs and composite panels (sandwich panels), where uncalculated stressed skin effects may lead to tearing of the fixings. The stressed skin action of various forms modern roof systems was presented by Davies and Lawson [7].

Discussions by the authors with local steel fabricators in Northern Ireland have indicated that less stringent deflection limits than those given by SCI are often used in practice for frames with single skin profiled metal cladding, and these deflection limits are also shown in Table 1. This paper investigates the effect of both sets of deflection limits using a genetic algorithm (GA) that optimizes the weight of the frame.

The design optimization of steel portal frames has previously been considered [8-10]. Saka [8] used a binary-coded GA to minimize the weight of a portal frame, subject only to gravity load, for which the position of lateral and torsional restraints were fixed; the frame design was subsequently shown to be controlled by lateral-torsional buckling. Four distinct discrete 
variables were used, namely, the cross-section sizes of the columns and rafters, and both length and depth of the eaves haunch. The optimization procedure identified the most appropriate sections for the members from a list of standard universal beam sections; similarly, the most appropriate haunch size was selected from a list of discrete haunch dimensions.

Issa and Mohammad [9] continued the work of Saka and used a binary-coded GA with a number of population groups implementing genetic operations in parallel, referred to as distributed GA, to optimize the same portal frame as Saka, again using the same fixed position of lateral and torsional restraints. A binary string length of five bits was applied that included both universal beam and universal column sections. A number of variable mutation schemes were proposed to improve the diversity of the population that were shown to increase the probability of achieving the optimum solution.

More recently, Kravanja et al. [11] used parametric mixed-integer non-linear programming approach to optimize the design of single-story industrial steel building structure. The minimal mass of structure, in accordance with the optimal frame spacing and the optimal standard crosssections were obtained through the optimization. The first-order elastic method was also applied to structural analysis and the building was designed according to Eurocode specifications. It was observed that the eaves haunches were not considered in this research.

The effect of serviceability constraints on frame weight for fully laterally-restrained hotrolled steel portal frames has therefore not been considered explicitly in either of these previous researches. In addition, for the steel portal frame with haunch rafters, neither Saka nor Issa and Mohammad, as mentioned above, considered plastic design. In this paper, both issues are addressed and the effect of serviceability limits on the minimum weight of frames is investigated, relative to the minimum weight obtained from plastic design; frames of spans varying from $15 \mathrm{~m}$ to $50 \mathrm{~m}$ are considered.

Furthermore, for an optimization problem that has continuous variables, binary-coded GA has difficulty in accurately achieving the optimum solution, since more accurate results require a longer binary string to be used. On the other hand, real-coded genetic algorithms (RC-GA) have been successfully applied to optimization problems having continuous variables [12-14]. In addition, the flexibility of the RC-GA is such that the algorithm can effectively search for the optimum solution for problems containing both discrete and continuous variables. In addition to the above-mentioned investigation into the effects of the deflection limits, this paper therefore describes the formulation of a real-coded niching genetic algorithm (RC-NGA) used to optimize the column and rafter members as discrete decision variables, and the size of the haunch as continuous decision variables. 


\section{Reference Frame}

The geometry of the portal frame shown in Fig. 1 is considered in this paper, in which $\mathrm{L}_{\mathrm{f}}$ is the frame span; $h_{f}$ is the column height; $s_{f}$ is the rafter length; $\theta_{f}$ is the pitch. Details of the Reference Frame used for the benchmark is shown in Fig. 2; the geometry of the frame and section sizes for the column and rafter are taken from a worked example in an SCI guide on portal frame design [2]. As can be seen, the Reference Frame has a span of $30 \mathrm{~m}$, height-to-eaves of $7 \mathrm{~m}$, and pitch of $6^{\circ}$. The distance between adjacent frames is $6 \mathrm{~m}$, which is considered to be typical for industrial buildings in the UK. It should be noted that second-order effects are not considered, since the geometry satisfies the requirements for in-plane stability of the sway check method, described in BS 5950 [3]. Based on the geometry of the Reference Frame, the two sets of deflection limits of the Reference Frame are shown in Table 2.

The column and rafter sections are 533x210x101UB and 457x191x67UB, respectively, both in S275 steel and Table 3 summarises the properties of the sections. The length of the eaves haunch is $10 \%$ of the frame span, and such a length is considered to be typical for portal frames designed plastically. The eaves haunches are assumed to be fabricated from the same section size as that of the rafter.

Fig. 3 shows the parameters used to define the eaves haunch size in this paper. As can be seen, the haunch length, $\mathrm{L}_{\mathrm{h}}$, is measured from the centre-line of column to the end of the haunch; the haunch depth (or cutting depth), $\mathrm{D}_{\mathrm{h}}$, is measured from the underside of rafter to the bottom of the eaves haunch.

The dead load (DL) and live load (LL) acting on the Reference Frame, as described in the SCI worked example [2], are as follows:

$$
\begin{array}{ll}
\text { DL: } & 0.66 \mathrm{kN} / \mathrm{m}^{2} \\
\text { LL: } & 0.60 \mathrm{kN} / \mathrm{m}^{2}
\end{array}
$$

\section{Load Combinations}

Under vertical load, in accordance with BS 5950 [3], the frame should be checked at ultimate and serviceability limit states:

$$
\begin{aligned}
& \mathrm{ULS}=1.4 \mathrm{DL}+1.6 \mathrm{LL} \\
& \text { SLS1 }=1.0 \mathrm{DL}+1.0 \mathrm{LL} \quad \text { (for absolute deflection) } \\
& \text { SLS2 }=1.0 \mathrm{LL} \quad \text { (for differential deflection relative to adjacent frame) }
\end{aligned}
$$

where

$$
\begin{array}{ll}
\text { ULS } & \text { is ultimate limit state } \\
\text { SLS } & \text { is serviceability limit state }
\end{array}
$$

Table 4 summarises the deflections determined for the Reference Frame under the 
serviceability limit state. As can be seen, the Reference Frame does not satisfy the SCI recommendations for deflection limits at the apex, but satisfies the less stringent deflection limits.

\section{Ultimate Limit State Design}

\subsection{Frame analysis}

\subsubsection{Rigid-plastic analysis}

Fig. 4 shows the rigid-plastic collapse mechanism of a portal frame under a uniformly distributed vertical load (w). As can be seen, the frame collapses with the first plastic hinge forming at the underside of the haunch of the column, and the second plastic hinge forming along the rafter near to the apex; the sections between the hinges are assumed to remain rigid [12].

The horizontal position of the second hinge $(\mathrm{x})$, measured relative to the centreline of the left hand side column, can be determined from the following virtual work expression:

$$
M_{p c}(\phi+\theta)+M_{p r} \theta=w x \frac{x \theta}{2}+w\left(\frac{L}{2}-x\right) x \theta
$$

where:

$\mathrm{M}_{\mathrm{pc}}$ is the reduced moment capacity of the column section

$\mathrm{M}_{\mathrm{pr}}$ is the reduced moment capacity of the rafter section

The collapse load, $\mathrm{w}_{\mathrm{c}}$, is the minimum value of $\mathrm{w}$ related to the variation with $\mathrm{x}$. The ratio $\mathrm{w}_{\mathrm{C}} / \mathrm{w}_{\text {design }}$ is known as the collapse load factor, $\lambda_{\mathrm{P}}$; the ratio $1 / \lambda_{\mathrm{P}}$ should be equal to or less than unity.

\subsubsection{Elastic analysis}

The general purpose finite element program ANSYS was used for the purpose of the elastic analysis. BEAM3 elements were used for the columns and rafters, while BEAM54 elements were used for the haunches, as BEAM54 elements possess offset properties [15].

The second moment of area of the cross-section at the haunch (see Fig. 5) is calculated, based on the assumption that the thickness of the flange and web of the haunch are the same as those of the rafter. In accordance with Saka [8], the second moment of area of the haunch is given by:

$$
I_{x}=I_{u}+A_{u}\left[0.5 D_{u}+D_{h}-y_{x}\right]^{2}+I_{h}+A_{h}\left(y_{x}-y_{h x}\right)^{2}
$$

where:

$\mathrm{I}_{\mathrm{X}} \quad$ is the moment of inertia of haunch section

$I_{u} \quad$ is the moment of inertia of rafter section

$\mathrm{A}_{\mathrm{u}} \quad$ is the cross-sectional area of rafter section 

$\mathrm{A}_{\mathrm{h}} \quad$ is the cross-sectional area of cutting haunch
$D_{u} \quad$ is the depth of rafter section
$\mathrm{D}_{\mathrm{h}} \quad$ is the depth of cutting haunch
$\mathrm{y}_{\mathrm{x}} \quad$ is the distance to centroid of overall haunch cross section.

The column is divided into two elements, with the first element defined from the column base to the underside of eaves haunch; the second element is defined from the underside of eaves haunch to the intersection of the centrelines of the column and rafter. The eaves haunch is divided into four elements, which is sufficient to check the local capacity. The rafter is divided into 40 elements to determine the critical section for the local capacity check of the rafter near the apex. The internal forces, namely, axial forces, shear forces, and bending moments at these sections are used to carry out the member checks.

\subsection{Ultimate limit state design requirements}

In this paper, in order to determine the minimum weight solution for the frame, full lateral restraint is assumed; member buckling checks will therefore not be undertaken. As described in Section 2, the geometry of the Reference Frame satisfies the requirements for in-plane stability of the sway check method, described in BS 5950 [3], and so second-order effects can be ignored for this particular frame [16]. It should be noted that second-order effects are not considered as part of the parametric study described Section 8, as a rigid-plastic model is adopted. However, if these results are required to include second-order effects, the amplified moment method could be adopted and applied to the vertical loads $[2,17]$.

Members having full lateral restraint should be designed to satisfy the requirements for local capacity. Specifically, the members are checked for local capacity under shear, axial, or moment capacity, and combined moment and axial force [3].

\subsubsection{Shear capacity}

The shear force, $\mathrm{F}_{\mathrm{v}}$, should not be greater than the shear capacity, $\mathrm{P}_{\mathrm{v}}$, given by:

$$
\mathrm{F}_{\mathrm{v}} \leq \mathrm{P}_{\mathrm{v}}
$$

The shear capacity is given by:

$$
P_{v}=0.6 p_{y} A_{v}
$$

where:

$\mathrm{p}_{\mathrm{y}} \quad$ is the yield stress of steel

$A_{v} \quad$ is the shear area

The shear area for an I section is given by:

$$
A_{v}=t_{w} D
$$

where: 

$t_{w} \quad$ is the thickness of web section
$\mathrm{D}$ is the overall depth of section

\subsubsection{Axial capacity}

The axial capacity should be checked to ensure that the axial force $F_{c}$ does not exceed the axial capacity of the member.

$$
F_{c} \leq p_{y} A_{g}
$$

where:

$$
\mathrm{A}_{\mathrm{g}} \text { is the gross area of section }
$$

\subsubsection{Moment capacity}

The moment should not be larger than the moment capacity of the cross section, $\mathrm{M}_{\mathrm{cx}}$.

$$
\mathrm{M}_{\mathrm{x}} \leq \mathrm{M}_{\mathrm{cx}}
$$

where:

$\mathrm{M}_{\mathrm{x}}$ is the moment applied to the critical section

$\mathrm{M}_{\mathrm{cx}}$ is the moment capacity of the section

The moment capacity depends on the shear strength. BS 5950 [3] defines two methods of determining the moment capacity of section, namely, low shear, defined as $F_{v} \leq 0.6 P_{v}$, and high shear, defined as $\mathrm{F}_{\mathrm{v}}>0.6 \mathrm{P}_{\mathrm{v}}$ conditions.

\subsubsection{Reduced moment capacity}

When members are subject to both compression and bending, the moment capacity, $\mathrm{M}_{\mathrm{cx}}$, should be reduced, depending upon the axial force and cross-section geometry of the member.

In plastic design, the reduced plastic moment capacity of the section is calculated as follows:

$$
\mathrm{M}_{\mathrm{rx}}=\mathrm{p}_{\mathrm{y}} \mathrm{S}_{\mathrm{rx}}
$$

where:

$\mathrm{M}_{\mathrm{rx}}$ is the reduced moment capacity of section

$\mathrm{S}_{\mathrm{rx}} \quad$ is the reduced plastic modulus

\subsubsection{Combined moment and axial force}

In elastic design, the local capacity check is as follows:

$$
\frac{F_{c}}{A_{g} p_{y}}+\frac{M_{x}}{M_{c x}} \leq 1
$$

\section{Optimization Model}

The most appropriate steel sections for the columns and rafters are selected from a list of 72 standard sections of S275 steel grade given in the SCI Blue Book [17]. The number of UB sections from the list having the same depth is shown in Fig. 6. As can be seen, the sections with 
the depth in the middle of the list account for the vast majority of sections, as compared to those sections at the two ends of the list. The size of the eaves haunch is also considered, for three types of eaves haunch.

- Haunch A: Haunch length fixed as $10 \%$ of the span; the haunch uses the same section as the rafter section (i.e., $\mathrm{D}_{\mathrm{h} 0}$ is equal to $\mathrm{D}_{\mathrm{u}}$ as shown in Fig. 3 and 7). Thus, the decision variables are the discrete column and rafter sections.

- Haunch B: Identical to Haunch A except that the haunch length is varied in the range of $[5 \%, 25 \%]$ of the frame span. The decision variables are the column and rafter sections (discrete) and the length of the haunch (continuous).

- Haunch C: Identical to Haunch B except that, in addition to varying the haunch length, the haunch depth is varied in the range of $\left[0.05 \mathrm{D}_{\mathrm{h} 0}, 4 \mathrm{D}_{\mathrm{h} 0}\right]$. The decision variables are the column and rafter sections (discrete) and the length and depth of the haunch (continuous).

The objective of the overall design optimization is to determine the portal frame having the minimum steel material weight, whilst satisfying the design requirements. The weight of the frame depends on the cross-section sizes of members that are discrete design variables and sizes of the haunch, i.e., haunch length and haunch depth, as continuous variables. The objective function can be expressed in terms of the weight of the primary members per square metre of the floor area as follows:

$$
\text { Minimize W }=\frac{1}{L_{f} b_{f}}\left(\sum_{i=1}^{m} w_{i} l_{i}+\sum_{j=1}^{n} w_{h j}\right)
$$

where:

$\mathrm{W}$ is the weight of main frame per square metre of floor area

$w_{i} \quad$ are the weight per unit length of members

$l_{i} \quad$ are the lengths of hot-rolled steel structural members

$m \quad$ is the number of members.

$w_{h}$ are the weight of a single haunch

$n \quad$ is a number of eaves haunch

For plastic design the constraints are as follows:

$$
g_{1}=\frac{F_{v}}{0.6 p_{y} A_{v}}-1 \leq 0
$$




$$
\begin{aligned}
& \mathrm{g}_{2}=\frac{\mathrm{F}_{\mathrm{c}}}{\mathrm{p}_{\mathrm{y}} \mathrm{A}_{\mathrm{g}}}-1 \leq 0 \\
& \mathrm{~g}_{3}=\frac{\mathrm{M}_{\mathrm{x}}}{\mathrm{M}_{\mathrm{cx}}}-1 \leq 0 \\
& \mathrm{~g}_{4 \mathrm{P}}=\frac{\mathrm{M}_{\mathrm{x}}}{\mathrm{M}_{\mathrm{rx}}}-1 \leq 0 \\
& \mathrm{~g}_{5}=\frac{1}{\lambda_{\mathrm{P}}}-1 \leq 0 \\
& g_{6}=\frac{\delta_{e}}{\delta_{e}^{u}}-1 \leq 0 \\
& g_{7}=\frac{\delta_{a}}{\delta_{a}^{u}}-1 \leq 0
\end{aligned}
$$

where $\lambda_{p}=$ collapse load factor; $\delta_{e}$ and $\delta_{a}=$ deflections at eaves and apex, respectively, and the superscript $u$ indicates the maximum permissible deflection.

For elastic design, the constraint $g_{5}$ is excluded and the design constraint $\mathrm{g}_{4 \mathrm{P}}$ is replaced by the constraint $\mathrm{g}_{4 \mathrm{E}}$ below:

$$
\mathrm{g}_{4 \mathrm{E}}=\frac{\mathrm{F}_{\mathrm{c}}}{\mathrm{A}_{\mathrm{g}} \mathrm{p}_{\mathrm{y}}}+\frac{\mathrm{M}_{\mathrm{x}}}{\mathrm{M}_{\mathrm{cx}}}-1 \leq 0
$$

The constraints for ultimate limit state design are $g_{1}$ to $g_{5}$ while the serviceability limit state design constraints are $g_{6}$ and $g_{7}$. Constraint $g_{1}$ is for shear capacity; $g_{2}$ is for axial capacity; $\mathrm{g}_{3}$ is for bending capacity; $\mathrm{g}_{4 \mathrm{P}}$ is for reduced moment capacity for plastic design; $\mathrm{g}_{4 \mathrm{E}}$ is for combined axial force and bending moment for elastic design; $g_{5}$ is the constraint for plastic load factor; $g_{6}$ and $g_{7}$ are for horizontal and vertical deflection limits, respectively (see Table 2). To solve the optimization problem, the procedure used here is to transform the constrained problem to an unconstrained one using a penalty method. The fitness function adopted has the form:

$$
\mathrm{F}=\mathrm{W}\left(1+\sum_{\mathrm{i}=1}^{\mathrm{n}} \mathrm{C}_{\mathrm{i}}\right)
$$

where:

$$
\begin{array}{ll}
F & \text { is the fitness function } \\
\mathrm{C}_{\mathrm{i}} & \text { is the constraint violation penalty } \\
\mathrm{n} & \text { is the number of design constraints }
\end{array}
$$

In this paper, penalty values are imposed empirically, in proportion to the severity of constraint violation. Through a numbers of trials, it was observed that two levels of constraint 
violation as shown in Eq. (11), are suitable to eliminate the infeasible solutions through the evolutionary process.

$$
\mathrm{C}_{i}=\left\{\begin{array}{ccc}
0 & \text { if } & \mathrm{g}_{\mathrm{i}} \leq 0 \\
\mathrm{~g}_{\mathrm{i}} & \text { if } & 0<\mathrm{g}_{\mathrm{i}} \leq 0.5 \\
5 \mathrm{~g}_{\mathrm{i}} & \text { if } & \mathrm{g}_{\mathrm{i}}>0.5
\end{array} \quad ;(\mathrm{i}=1, \ldots, \mathrm{n})\right.
$$

The proposed optimization procedure aims to minimize the value of the fitness function $\mathrm{F}$ in Eq. (10). This is achieved using a GA by minimizing the weight $\mathrm{W}$ and reducing the penalty values $\mathrm{C}_{\mathrm{i}}$ to zero.

\section{Real-coded niching genetic algorithm}

The design optimization considered in this paper contains mixed discrete and continuous decision variables. As demonstrated by Deb [12], RC-GA is appropriate for optimization problem having continuous decision variables. The benefit of RC-GA is that genetic operators are directly applied to the design variables without coding and decoding as with binary string GAs.

\subsection{Genetic operators}

RC-GA sometimes prematurely converges to a local optimum solution due to the domination of superior solutions in current population $[12,13]$. Also, using the RC-GA, Phan et. al. [18-19] observed that a large population size needs to be used in order to obtain the optimum solution consistently. Therefore, in this paper, a niching technique is applied to maintain the diversity of the population throughout the evolutionary process, thereby enhancing the convergence to the optimum solution. The niching strategy is conducted by selecting at random two individuals from the current population, namely $x^{(i)}$ and $x^{(j)}$. The normalized Euclidean distance [20] between the two solutions is:

$$
d_{i j}=\sqrt{\frac{1}{n} \sum_{k=1}^{n}\left(\frac{x_{k}^{(i)}-x_{k}^{(j)}}{x_{k}^{u}-x_{k}^{l}}\right)^{2}}
$$

where:

$$
\begin{array}{ll}
d_{i j} & \text { is a normalized Euclidean distance between } \boldsymbol{x}^{(i)} \text { and } \boldsymbol{x}^{(j)} \\
n & \text { is the number of decision variables } \\
x_{k}^{(i)} \text { and } x_{k}^{(j)} & \text { are the } k^{\text {th }} \text { decision variable values in the two vectors } \boldsymbol{x}^{(i)} \text { and } \boldsymbol{x}^{(j)} . \\
x_{k}{ }^{u} \text { and } x_{k}^{l} & \text { are the upper and lower bounds respectively of the } k^{\text {th }} \text { decision } \\
& \text { variable. }
\end{array}
$$

If this Euclidean distance is smaller than an empirical user-defined critical distance known as niching radius, these solutions then compete against each other for selection for subsequent 
crossover. The solution with a smaller value of the fitness function $\mathrm{F}$ is selected (Eq. 10). Otherwise, they are not compared and another solution $\boldsymbol{x}^{(j)}$ is selected at random from the population. If after a certain number of trials, no solution $\boldsymbol{x}^{(j)}$ is found to satisfy the critical distance, $\boldsymbol{x}^{(i)}$ is accepted. In this way, only solutions in same region (or niche) compete against each other for selection and crossover. Based on Eq. (12), the normalized Euclidean distance has a range from 0 to 1 .

The crossover operator for RC-GA applies the simulated binary crossover (SBX) formula directly to real variables [21]. Deb observed that with the crossover operator applied uniformly to the whole population, some search effort is wasted in the recombination of solutions from different region. A mating restriction scheme is therefore applied with RC-GA to prevent individuals in different niches from mating with each other. Only two individuals that are located within a normalized Euclidean distance smaller than a pre-defined distance, or in the same niche, should be allowed to become mating partners. For two solutions satisfying the mating restriction, the SBX operator is as follows:

$$
\begin{aligned}
& x_{k}^{(1, t+1)}=0.5\left[(1+\beta) x_{k}^{(1, t)}+(1-\beta) x_{k}^{(2, t)}\right] \\
& x_{k}^{(2, t+1)}=0.5\left[(1-\beta) x_{k}^{(1, t)}+(1+\beta) x_{k}^{(2, t)}\right]
\end{aligned}
$$

where:

$$
\begin{array}{ll}
\beta & \text { is the probability distribution function for crossover } \\
x_{k}^{(1, t)} \text { and } x_{k}^{(2, t)} & \text { are the values of the } k^{\text {th }} \text { decision variable for the parent } \\
& \text { solutions } \\
x_{k}^{(1, t+1)} \text { and } x_{k}^{(2, t+1)} & \begin{array}{l}
\text { are the values of the } k^{\text {th }} \text { decision variable for the children } \\
\text { created for the next generation. }
\end{array}
\end{array}
$$

To ensure the new values of the decision variable remain within the range $\left[x_{k}^{l}, x_{k}{ }^{u}\right]$, where $x_{k}^{l}$ and $x_{k}{ }^{u}$ are the lower and upper bounds, respectively, the probability distribution for the crossover operator has the form:

$$
\beta\left(\eta_{c}\right)=\left\{\begin{array}{ccc}
{[\alpha u]^{1 /\left(\eta_{c}+1\right)}} & \text { if } & u \leq 1 / \alpha, \\
{[1 / 2-\alpha u]^{1 /\left(\eta_{c}+1\right)}} & \text { if } & 1 / \alpha<u \leq 1
\end{array}\right.
$$

with: $\quad \alpha=2-\chi^{-\left(\eta_{c}+1\right)}$

$$
\chi=1+\frac{2}{x_{k}^{(2, t)}-x_{k}^{(1, t)}} \min \left[\left(x_{k}^{(1, t)}-x_{k}^{l}\right),\left(x_{k}^{u}-x_{k}^{(2, t)}\right)\right] ; \text { assuming } x_{k}^{(1, t)}<x_{k}^{(2, t)}
$$

where:

$\mathrm{u} \quad$ is a random number between 0 and 1

$\eta_{c} \quad$ is the distribution index for crossover; $\eta_{c}=1$ as recommended in [12].

It is worthwhile noting that the RC-GA with niching strategy applied in selection and 
cross-over operators is generally known as the real-coded niching genetic algorithm (RC-NGA). It should be noted that RC-NGA reduces to RC-GA if $d_{i j}=1.0$.

The other genetic operator applied in RC-NGA is the mutation such that one solution selected at random in the population is transformed using the polynomial mutation formula [13, 22] as follows:

$$
y_{k}^{(1, t+1)}=x_{k}^{(1, t+1)}+\left(x_{k}^{u}-x_{k}^{l}\right) \bar{\delta}
$$

where

$$
y_{k}^{(1, t+1)} \quad \text { is a new value obtained from the mutation operator and it replaces } x_{k}^{(1, t+1)}
$$

To ensure that no solution would be created outside the range of $x_{k}{ }^{u}$ and $x_{k}^{l}$ the parameter $\bar{\delta}\left(\eta_{m}\right)$ has the form [11]:

$$
\bar{\delta}=\left\{\begin{array}{ccc}
{\left[2 u+(1-2 u)(1-\delta)^{\eta_{m}+1}\right]^{1 /\left(\eta_{m}+1\right)}-1} & \text { if } & u \leq 0.5, \\
1-\left[2(1-u)+2(u-0.5)(1-\delta)^{\eta_{m}+1}\right]^{1 /\left(\eta_{m}+1\right)} & \text { if } & 0.5<u \leq 1
\end{array}\right.
$$

with:

$$
\delta=\min \left[\left(x^{(1, t+1)}-x_{k}^{l}\right),\left(x_{k}^{u}-x^{(1, t+1)}\right)\right] /\left(x_{k}^{u}-x_{k}^{l}\right)
$$

where:

$\mathrm{u} \quad$ is a random number between 0 and 1

$\eta_{m} \quad$ is the distribution index for mutation; $\eta_{m}=1$ as recommended in [12].

The best individuals in the population, depending on the adopted percentage of population, are retained and carried forward unchanged to the next generation. In this paper, $5 \%$ of best individuals are empirically kept as elite preservation for next generation. The rest of the new population is created by the three genetic operators of selection, crossover and mutation applied to the entire current population including elite individuals.

For discrete design variables, a technique that rounds off the real numbers obtained from the simulated binary crossover ( $\mathrm{SBX}$ ) and polynomial mutation to the nearest integer number is applied [23].

\subsection{Comparison of results of RC-NGA against Issa and Mohammad}

The benchmark frame adopted by Issa and Mohammad [9], as presented by Saka [8], is optimized using RC-NGA. Fig. 8 shows the geometry of the frame; the frame is of span of $20 \mathrm{~m}$, height to eaves of $5 \mathrm{~m}$ and pitch of $8.53^{\circ}$. The load acting on the frame is $4 \mathrm{kN} / \mathrm{m}$. It should be noted that the geometry of this frame satisfies the requirements for in-plane stability of the sway check method, described in BS 5950 [3], and so second-order effects can also be ignored.

Issa and Mohammad [9] adopted deflection limits of $h_{f} / 300$ and $L_{f} / 360$ for the eaves and apex, respectively, which are more stringent than both the SCI deflection limits and the 
deflection limits suggested by industry. It should be noted that the deflection limits by Issa and Mohammad [9] were checked at the same loads as the member checks, i.e. no distinction was made for the loads between ultimate limit state design and serviceability state for deflection checks. It should also be noted that although the optimisation conducted by Issa and Mohammad included member buckling effects, they reported in their paper that deflections limits governed this particular benchmark design; the frame is therefore suitable for use as a benchmark for comparison with RC-NGA.

The flowchart of the RC-NGA is shown in Fig. 9. As described in Section 5, in the RCNGA the cross-section sizes of members are treated as discrete variables, whilst the haunch sizes are processed as continuous variables. The population size in this design is 40 and the algorithm is terminated after 240 generations. Constant probabilities are assigned to both crossover and mutation operators. Based on a number of trials, a crossover probability $P_{c}$ of 0.9 is used throughout in this study. It was observed also that a mutation probability of 0.1 generated the best results. This finding agrees with the value of mutation probability used in [13]. The effect of niching radius $d_{i j}$ was also considered by varying from 0.1 to 1 with interval of 0.1 . It was found that $d_{i j}$ of 0.3 is suitable for tournament selection and crossover operators. It is worth noting herein that with the normalized niching radius near to unity, the diversity of whole population declines remarkably; this means that the superior candidates having better fitness values dominated the population. For the niching radius less than 0.45 , the diversity of population is still maintained.

Five random runs of the GA were carried out and the same minimum-weight solution was found each time. This demonstrates the reliability and robustness in converging to the optimum solution of the RC-NGA. Table 5 shows the frame details obtained from the design optimization. As can be seen, the optimum cross-section of the column is the same as that of Issa and Mohammad, as mentioned above, whilst the rafter section is smaller/lighter. This is because the larger size of the haunch, obtained by RC-NGA, has allowed a lighter section to be used for the rafter. Consistent with the findings of Issa and Mohammad, it was found that the vertical deflection check at the apex controls the design (i.e., $\mathrm{g}_{7}=0$ ).

As can be seen from Table 5, the total weight of the frame found by RC-NGA is approximately $15 \%$ lighter than that of Issa and Mohammad [9]. This saving can be attributed to the fact that continuous variables are used for the haunch size, as opposed to discrete sizes, allowing a lighter rafter section to be selected. A further optimization of the same frame was conducted using elastic and plastic design, ignoring any serviceability checks; the results are also 
shown in Table 5. As can be seen, a $28 \%$ and $43 \%$ saving in weight was achieved for elastic and plastic design, respectively.

\section{Optimization of Reference Frame}

In this Section, the optimization model described in Section 5 is applied to the Reference Frame using RC-NGA (Section 6) on a laptop computer (2 GHz CPU, 2GB RAM). The same RC-NGA parameters from the validation runs in Section 6.2 were used: population $=40 ; P_{c}=$ $0.9 ; P_{m}=0.1 ; d_{i j}=0.3 ;$ termination criterion $=240$ generations.

\subsection{Optimal plastic design}

The Reference Frame is optimized using plastic design under the ultimate limit state. As described in Section 2, the geometry of the Reference Frame satisfies the requirements for inplane stability of the sway check method, described in BS 5950 [3], and so second-order effects can be ignored for this particular frame. The collapse mechanism is as described in Section 3. The deflections, obtained at the eaves and apex are determined using the structural package ANSYS under serviceability load combinations (SLC).

The two sets of deflection limits are applied to examine the serviceability requirements. These procedures are embedded in the RC-NGA to evaluate each candidate solution in the population.

To verify further the capacity of RC-NGA, the frame having Haunch A was designed five times with different random seeds. It is worth noting that five runs are sufficient to generate an optimal design. It was observed that all five optimization runs generated the same solution with a weight of $20.21 \mathrm{~kg} / \mathrm{m}^{2}$ (see Table 6). This solution is the same as from the SCI design example [2]. The progress of the optimization process is shown in Fig. 10. The same problem was solved using RC-GA that lacks niching by setting the niching radius $d_{i j}$ to 1.0 . With a population of 40 the minimum weight that RC-GA obtained was $22.8 \mathrm{~kg} / \mathrm{m}^{2}$. Increasing the population threefold to 120 enabled RC-GA to reach the optimum weight of $20.21 \mathrm{~kg} / \mathrm{m}^{2}$ found by RC-NGA with a population of 40 .

It was observed that the first plastic hinge formed at the underside of eaves haunch, and the second plastic hinge formed near to apex as shown in Fig. 5, with a collapse load factor $\lambda_{\mathrm{P}}$, of 1.04 (or $\mathrm{g}_{5}=-0.04$ ). In addition, the unity factor for strength constraint at the shallow end of the eaves haunch is less than $0.87\left(\mathrm{~g}_{4 \mathrm{E}}=-0.13\right)$, which shows that the haunch part is elastic. This condition prevents a plastic hinge being formed at the shallow end of the eaves haunch, and so the assumption of a collapse mechanism shown in Fig. 5 is still valid.

It is interesting to observe that the frame failed under elastic design with a unity factor of 
1.3 (or $\mathrm{g}_{4 \mathrm{E}}=0.3$ ) for the local capacity check of combined bending and compression, at the underside of the eaves haunch on the column. Also, the unity factor for vertical deflection at the apex exceeded the upper bound $\left(\mathrm{g}_{7}=0.65\right)$ for SCI deflection limits (Table 2$)$.

Using Haunch B, five random runs of the GA were executed all of which gave the same solution of weight is $20.13 \mathrm{~kg} / \mathrm{m}^{2}$, with the same cross-section sizes as Haunch A (see Table 6). On average, 8800 function evaluations (FEs) were required. The collapse mechanism as shown in Fig. 5 was observed; $g_{5}=-0.02$.

Table 6 also shows that the optimum solution for Haunch $\mathrm{C}$ has a smaller cross-section size for the rafter. The minimum weight of $19.21 \mathrm{~kg} / \mathrm{m}^{2}$ is $4.95 \%$ lighter than Haunch $\mathrm{A} ; \mathrm{g}_{5}=0$. Haunch C clearly shows that fixing the haunch length (design using Haunch A) and/or depth (design using Haunch B) a priori leads to suboptimal solutions. Five random runs of the GA were also carried out for optimizing the frame having Haunch C; it was observed 9600 FEs were required on average. It is worth noting that the industry serviceability constraints were slack for all three haunch designs. The time for RC-NGA to generate the optimal solution for Haunch A, $\mathrm{B}$ and $\mathrm{C}$ is $12 \mathrm{hrs}, 12.45 \mathrm{hrs}$ and $13.0 \mathrm{hrs}$, respectively.

\subsection{Optimal elastic design}

Five RC-NGA runs using different random seeds were performed for each haunch design. The results are summarised in Table 7. For Haunch A, the same solution of weight $22.43 \mathrm{~kg} / \mathrm{m}^{2}$ was obtained in 5 runs out of 5 . The local capacity check for the ultimate limit state is active, i.e. $\mathrm{g}_{4 \mathrm{E}}=-0.02$, for the combined bending and compression at the underside of the eaves haunch of the column. The solution obtained for Haunch B (5 runs out of 5) has a weight of $22.30 \mathrm{~kg} / \mathrm{m}^{2}$. The ultimate limit state constraints govern the design; $\mathrm{g}_{4 \mathrm{E}}=-0.02$ at the underside of the eaves haunch on the column. For Haunch $C$ the minimum weight of $21.12 \mathrm{~kg} / \mathrm{m}^{2}$ is $5.84 \%$ less than Haunch A. It was observed that 5 out of 5 runs generated the same solution as shown. The local capacity check at the shallow end of the haunch governs the design under combined moment and compression, $\mathrm{g}_{4 \mathrm{E}}=-0.01$. As in the preceding plastic design approach, Haunch $\mathrm{C}$ shows that prespecifying the length and/or depth of the haunch leads to designs that are local optima (Haunch $\mathrm{A}$ and $\mathrm{B})$.

\subsection{Optimal design with SCI serviceability deflection limits}

The frames optimized above using plastic and elastic design approaches respectively were checked with reference to the SCI serviceability deflection limits. The vertical apex deflection 
constraint exceeded the upper bound for all three haunch types. This means that SCI serviceability limit state (Table 2) controls the design of the Reference Frame.

The Reference Frame was therefore optimized again, with the SCI deflection limits incorporated this time. All the parameters for RC-NGA were kept the same. For each haunch design A-C, the same solution was obtained 5 times out of 5 . The results are summarised in Table 8 . The vertical deflection at the apex (constraint $\mathrm{g}_{7}$ ) is binding in all three haunch designs A-C. The cheapest solution is Haunch $\mathrm{C}$ (in which the haunch length and depth are allowed to vary) and has a weight $24.3 \mathrm{~kg} / \mathrm{m}^{2}$. This is $15 \%$ and $27 \%$ heavier than the optimal elastic and plastic designs (Haunch C), respectively. As compared with industry serviceability limits, the unity factor for the vertical deflection at the apex is much smaller than the upper bound, which the maximum unity factor is 0.38 (i.e., $\mathrm{g}_{7}=-0.62$ ) for the frame having Haunch A.

\section{Parametric study}

In the previous Section, it was shown that the SCI serviceability limits result in a design for the Reference Frame which is heavier than that obtained using serviceability limits based on less stringent industry limits This Section investigates the effect of serviceability limit states on the optimum weight of portal frames. It should be noted that second-order effects are not considered as part of the parametric study, in order to allow a comparison to be made between rigid-plastic and elastic design. Second-order effects could potentially increase the frame weights, and if the reader wished these to be considered for a particular frame, reference is made to the amplified moments method which could be applied to the vertical loads, as described in BS 5950 [3].

Spans considered in this study are varied from $15 \mathrm{~m}$ to $50 \mathrm{~m}$ and height to eaves from $5 \mathrm{~m}$ to $10 \mathrm{~m}$; the pitch and frame spacing for all frames are the same as before of $6^{\circ}$ and $6 \mathrm{~m}$, respectively. The frames are subject to a design vertical dead load of $0.26 \mathrm{kN} / \mathrm{m}^{2}$ and a design vertical live load of $0.6 \mathrm{kN} / \mathrm{m}^{2}$ [2].

The optimal designs for the frames considered in this Section are obtained using RC-NGA with genetic parameters as described previously. Four alternative Design Options (DO) are considered:

DO1: ULS plastic only

DO2: SLS based on suggestions by industry + ULS plastic

DO3: SLS based on suggestions by industry + ULS elastic

DO4: SLS based on SCI recommendations + ULS elastic

For each case, the minimum frame weight was obtained (in terms of $\mathrm{kg} / \mathrm{m}^{2}$ ) from 5 runs. It was observed that the optimum solution for each frame was obtained 5 times out of 5 . On average, it took 12.30 hours and 9400 FEs per optimization run. Fig. 11 shows the contour of 
minimum weight of frames under DO1 for the case of Haunch C. As can be seen, there is a monotonic trend of increase in the frame weight when both frame span and column height increase.

Fig. 12 shows the ratio of the results of DO2/DO1, again for the case of Haunch C. As can be seen, for frame spans greater than $25 \mathrm{~m}$ and with a height to eaves greater than $6.5 \mathrm{~m}$, only a $4 \%$ increase in frame weight is required to satisfy serviceability limit state based on suggestions by industry. For other frame geometries, a larger increase in frame weight is required. For example, a frame span of $20 \mathrm{~m}$ and a height to eaves of $10 \mathrm{~m}$ will require a $14 \%$ increase in frame weight from DO1 in order to satisfy DO2.

To investigate the effect of frame weights using elastic design, Fig. 13 shows the ratio of the results of DO3/DO1, again for the case of Haunch C. It is interesting to observe that for frames having span between $30 \mathrm{~m}$ and $40 \mathrm{~m}$, and column heights between $7 \mathrm{~m}$ and $8 \mathrm{~m}$, the difference between elastic and plastic design is small, approximately $2 \%$.

Fig. 14 shows the ratio of results of DO4/DO1 for the case of Haunch C. It can be seen that for frame spans of $50 \mathrm{~m}$, the SCI deflection limits results in an increase in frame weights by more than a factor of two. However, for shorter frame spans, the increase in frame weight is only $12 \%$.

In the designs considered in the parametric study, it was noted that the optimum haunch length varied only from $9 \%$ to $16 \%$ of the frame span. In order to investigate the effect of allowing the haunch length to vary, Fig. 15 shows the ratio of results for Haunch $\mathrm{C} / \mathrm{Haunch} \mathrm{A}$ for the case of DO3. As can be seen, there is a potential saving in frame weight of $10 \%$ that can be achieved by allowing the haunch size to vary. However, when the same study was repeated for the case of DO2, the potential saving in frame weight was negligible.

\section{Conclusions}

A real-coded niching enhanced GA was developed for the optimization of hot-rolled steel portal frames with eaves haunches. The frames were considered to be fully laterally-restrained, and so member buckling checks were ignored. Furthermore, second-order effects were ignored. Both plastic and elastic design approaches were considered.

The optimization model considered the local capacity constraints for ultimate limit state as specified in BS 5950 [3] and two sets of deflection limits, one based on SCI recommendations and a second based on less stringent limits for single skin roofs. Results for a Reference Frame, taken from an SCI example [2], are included for illustration purposes. The results show that adoption of the niching technique in selection process and crossover was highly effective in maintaining diversity in the population and thus preventing premature convergence due to over 
representation of the best individuals in the mating pool. With the niching strategy, it was possible to use a much smaller population in the GA optimization. For example, for Haunch A for the Reference Frame used here, niching enabled reduction of the size of the population by a factor of 3. This led to a reduction in the CPU time by $66.7 \%$. Overall, the results show that the GA developed is highly robust, efficient and stable. For the range of problems considered, several runs with random initial seeds were enough to find the same best solution consistently.

As expected, it was shown that plastic design produces a more economical design than elastic design when the column height of the frame is less than $7.5 \mathrm{~m}$; for instance, the saving up to $12 \%$ lighter in weight is observed for frame span of $30 \mathrm{~m}$ and column height of $6 \mathrm{~m}$. When SCI deflection limits are considered, the optimum frame obtained from the SCI deflection limits is observed to be up to twice as heavy as plastic design for a frame span $50 \mathrm{~m}$. However, the effect of serviceability limits based on the less stringent limits has a much smaller effect on frame design. The increase in frame weight is only up to $4 \%$, for the majority of frames considered. Varying haunch sizes, both length and depth, shows the potential for savings as compared to the eaves haunch length fixed with $10 \%$ of frame span and haunch depth for elastic design, although not for plastic design. Whilst considerations of fabrication costs, particularly of connections, may be more important to fabricators, the results of the parametric study undertaken can be used to inform fabricators of the sensitivity of a given frame to serviceability deflection limits.

\section{Acknowledgement}

The financial support from the Queen's University Belfast is gratefully acknowledged. 


\section{References}

[1] Davies JM., and Brown BA. Plastic design to 5950. Great Britain: The Steel Construction Institute, 1996.

[2] Salter PR., Malik AS., and King CM. Design of single-span steel portal frames to BS 5950-1: 2000. SCI publication P252. Ascot: The Steel Construction Institute, 2004.

[3] British Standards. BS 5950: Structural use of steelworks in building. Part 1. Code of practice for design - Rolled and welded sections. London: British Standards Institution, 2001.

[4] Lim JBP., and Nethercot DA. Serviceability design of a cold-formed steel portal frame having semi-rigid joints. Steel \& Composite Structures, 2003, 3(6), 451-474.

[5] Lim JBP., and Nethercot DA. Finite element idealization of a cold-formed steel portal frame. Journal of Structural Engineering, ASCE, 2004, 130(1), 78-94.

[6] SCI Advisory Desk. AD-090: Deflection limits for pitched roof portal frames (Amended). Ascot: The Steel Construction Institute, 2010.

[7] Davies JM., and Lawson RM. Stressed skin action of modern steel roof systems. The Structural Engineer, 1999, 77(21), 30-35.

[8] Saka MP. Optimum design of pitched roof steel frames with haunched rafters by genetic algorithm. Computers and Structures, 2003, 81, 1967-1978.

[9] Issa HK., and Mohammad FA. Effect of mutation schemes on convergence to optimum design of steel frames. Journal of Constructional Steel Research, 2010, 66(7), 954-961.

[10] Wrzesien A., Lim JBP., and Nethercot DA. Optimum joint detailed for a general cold-formed steel portal frame. Advances in Structural Engineering, 2012, 15(9), 1635-1651.

[11] Kravanja, S., Turkalj, G., Šilih, S., and Žula, T. Optimal design of single-story steel building structures based on parametric MINLP optimization. Journal of Constructional Steel Research, 2013, 81, 86-103.

[12] Deb K. Multi-objective optimization using evolutionary algorithms. Chichester: John Wiley and Sons, Inc, 2001.

[13] Deb K., and Gulati S. Design of truss-structures for minimum weight using genetic algorithms. Finite Element in Analysis and Design, 2001, 37, 447-465.

[14] Yu EL, and Sugathan PN. Ensemble of niching algorithms. Information Sciences, 2010, 180, 28152833.

[15] ANSYS Inc. Programmer's manual for mechanical APDL. USA: SAS IP, Inc, 2009.

[16] Lim JBP., King CM., Rathbone AJ., Davies JM., and Edmondson V. Eurocode 3 and the in-plane stability of portal frames. The Structural Engineer, 2005, 99, 1-7.

[17] Steelwork design guide to BS 5950-1:2000. Section properties, Member capacities, Volume 1, 7th edition. SCI publication P202. Ascot: The Steel Construction Institute, 2007. 
[18] Phan DT., Lim JBP., Siew C., Tanyimboh T., Issa H., and Sha W. Optimization of cold-formed steel portal frame topography using real-coded genetic algorithm. Procedia Engineering 14, 2011, 724-733.

[19] Phan DT., Lim JBP., Sha W., Siew C., Tanyimboh T., Issa H., and Mohammad F. Design optimization of cold-formed steel portal frames taking into account the effect of topography. Engineering Optimization, 2013, DOI:10.1080/0305215X.2012.678493.

[20] Deb K. An efficient constraint handling method for genetic algorithms. Computer Methods in Applied Mechanics and Engineering, 2000, 186, 311-338.

[21] Deb K., and Agrawal RB. Simulated binary crossover for continuous space. Complex Systems, 1995, 9(2), 115-148.

[22] Deb K. Mechanical component design using genetic algorithms. In: Dasgupta, D., and Michalewicz, Z., eds., Evolutionary Algorithms in Engineering Applications. New York: Springer, 1997, 495-512.

[23] Doğan E., and Saka MP. Optimum design of unbraced steel frames to LRFD-AISC using particle swarm optimization. Advances in Engineering Softwares, 2012, 46, 27-34. 


\section{FIGURES}

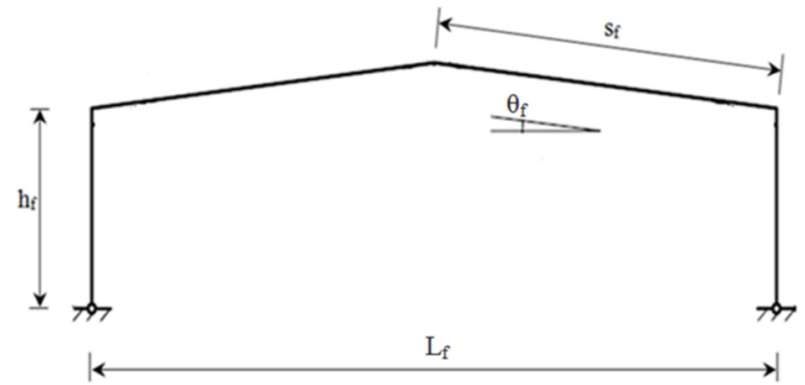

Fig. 1 Parameters used to define portal frames (based on centerline dimensions)

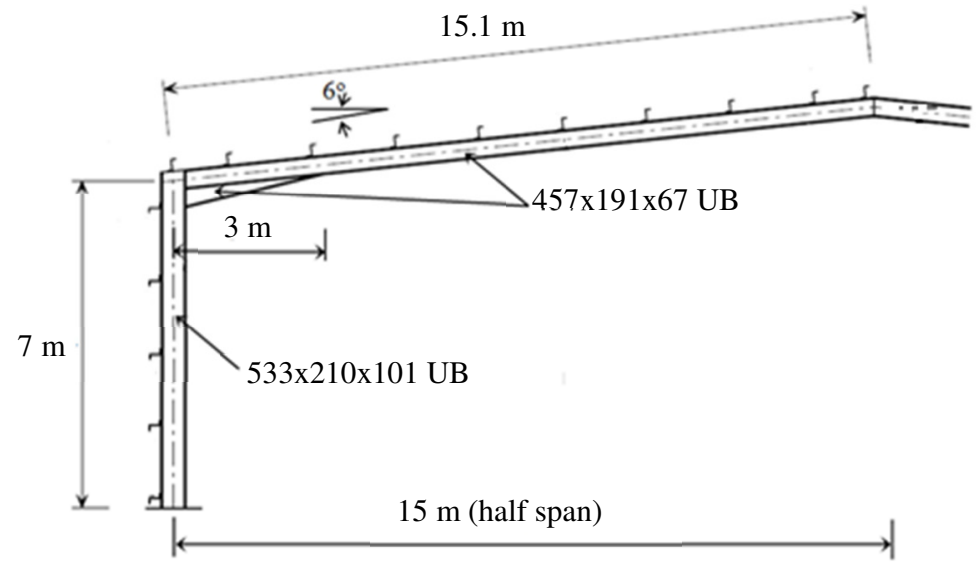

Fig. 2 Details of Reference Frame [3]

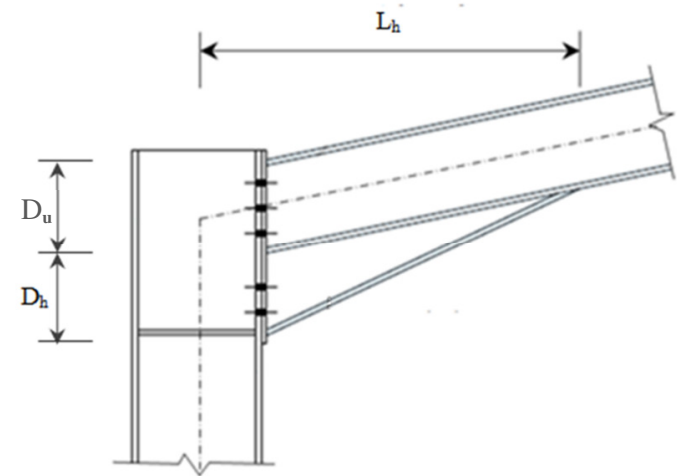

Fig. 3 Parameters used to define eaves haunch [3] 


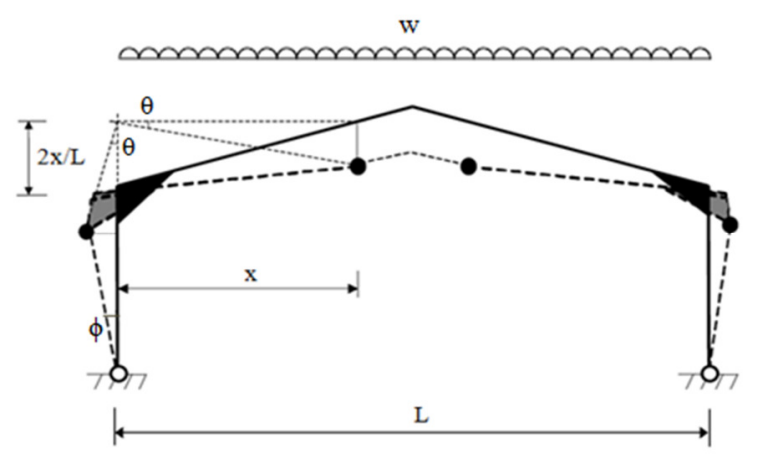

Fig. 4 Plastic collapse mechanism under symmetrical gravity load [1]

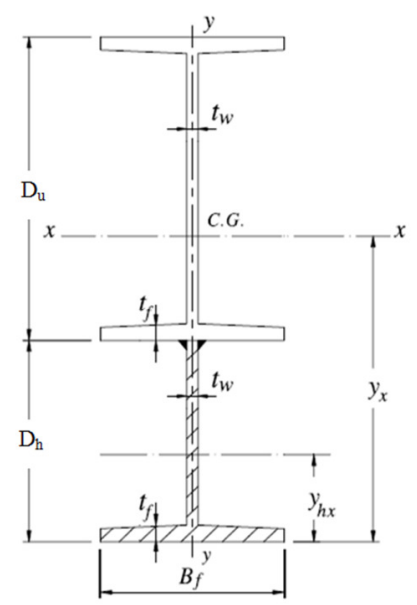

Fig. 5 Cross-section of eaves haunch after Saka [5]

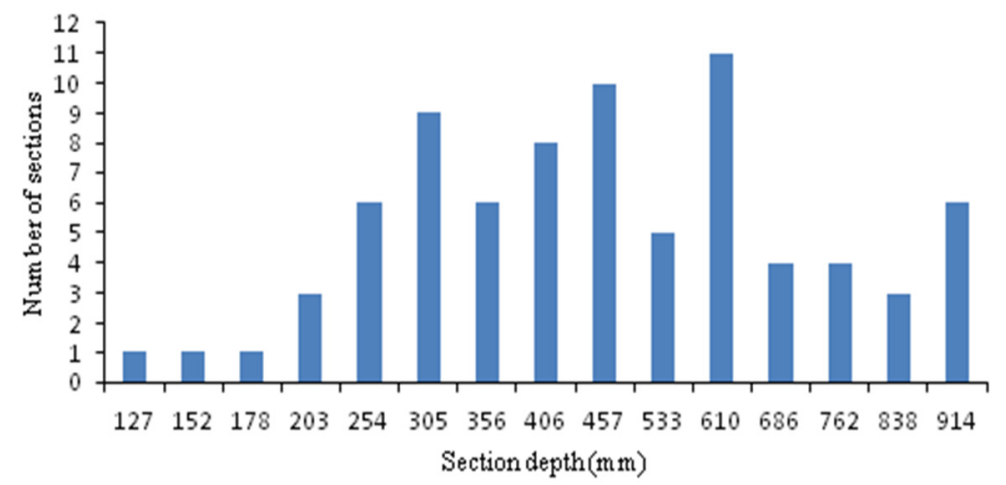

Fig. 6 Distribution of universal beam sections relative to section depth 


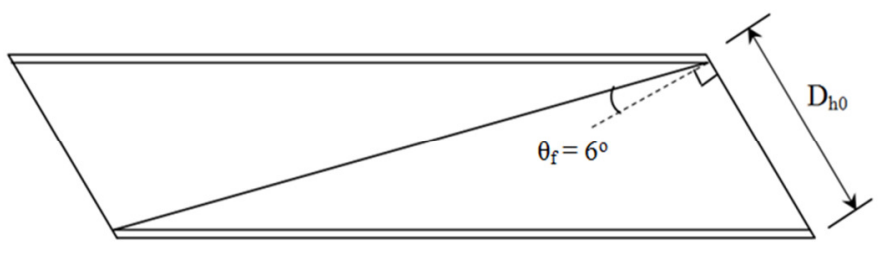

Fig. 7 Details of eaves haunch cut from rafter section

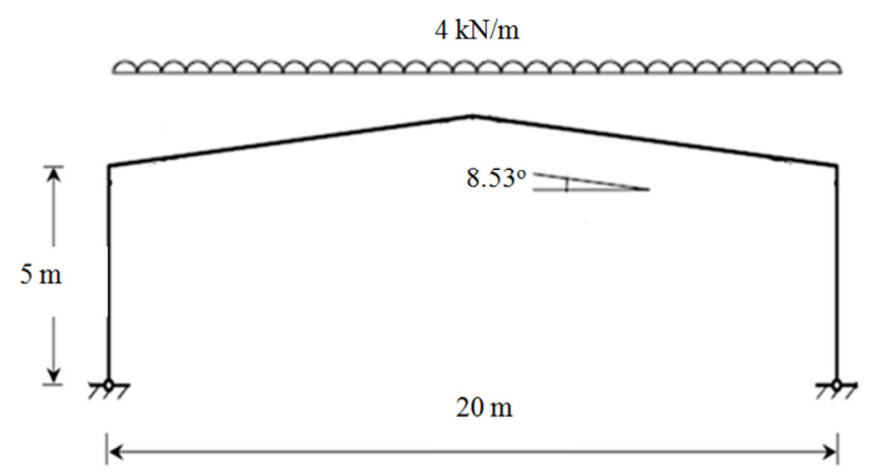

Fig. 8 Geometry of portal frame after Issa and Mohammad [6]

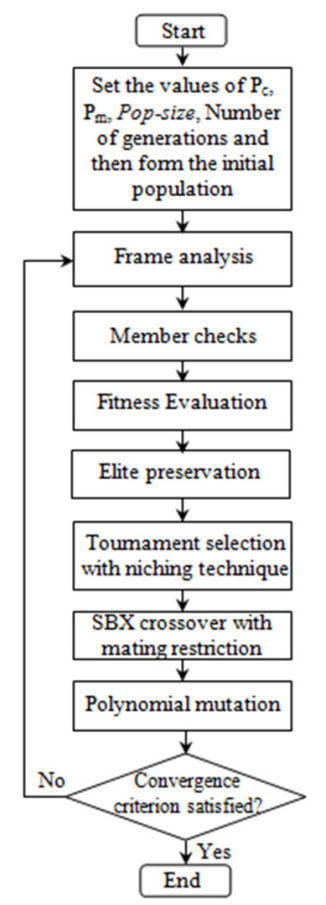

Fig. 9 Flowchart of RC-NGA 


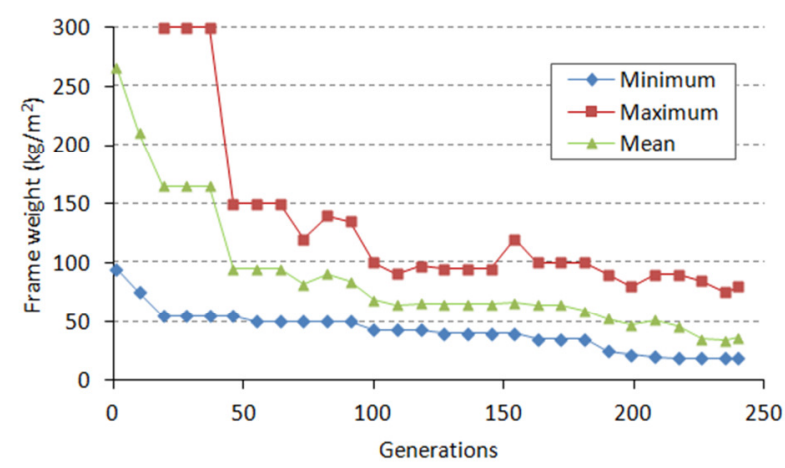

Fig. 10 Convergence history of RC-NGA for Reference Frame having Haunch A

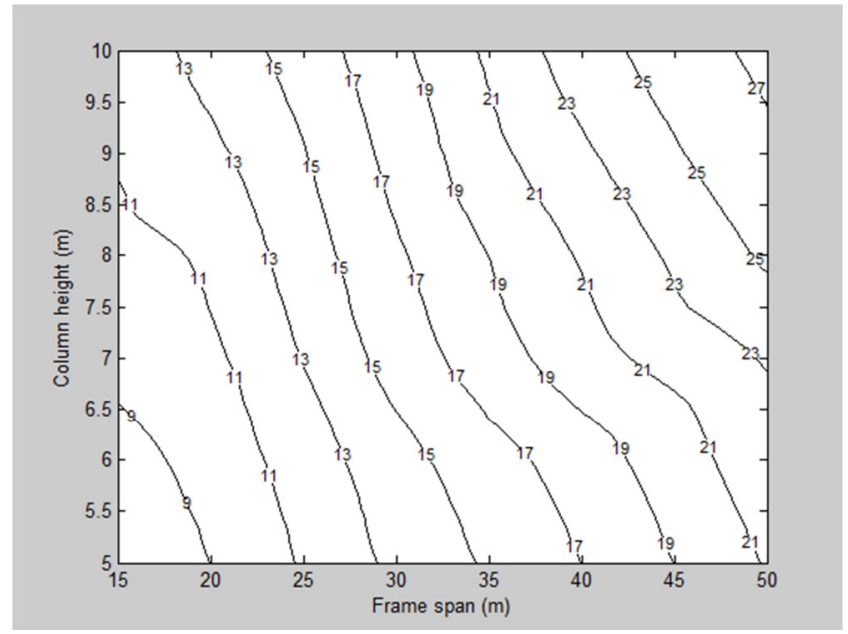

Fig. 11 Contour of frame weight $\left(\mathrm{kg} / \mathrm{m}^{2}\right)$ under DO1 using Haunch C

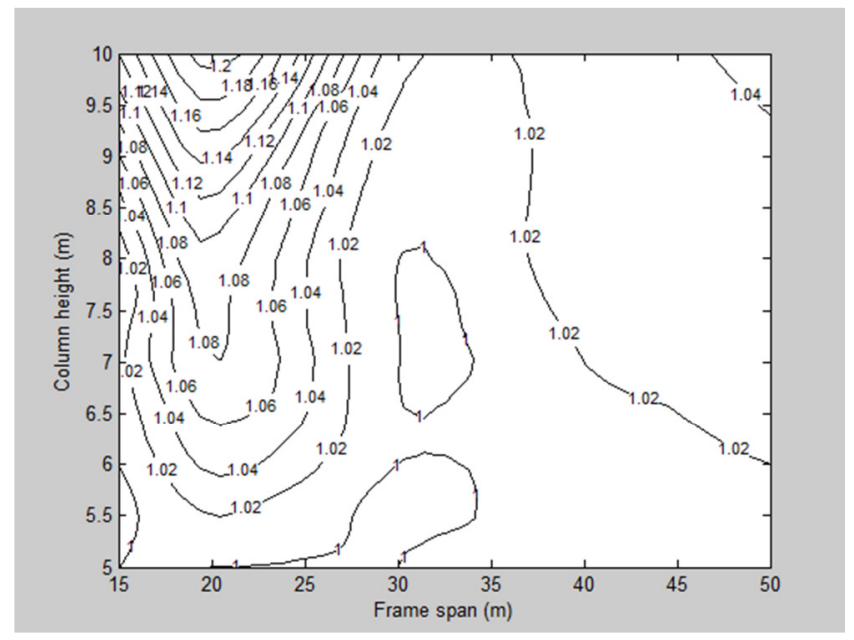

Fig. 12 Contour of DO2/DO1 using Haunch C 


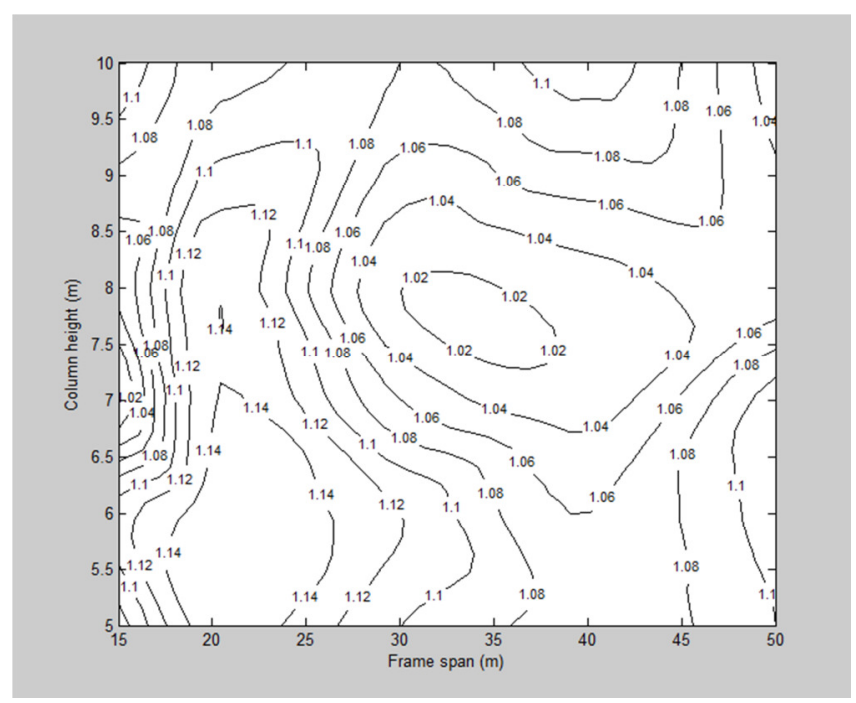

Fig. 13 Contour of DO3/DO1 using Haunch C

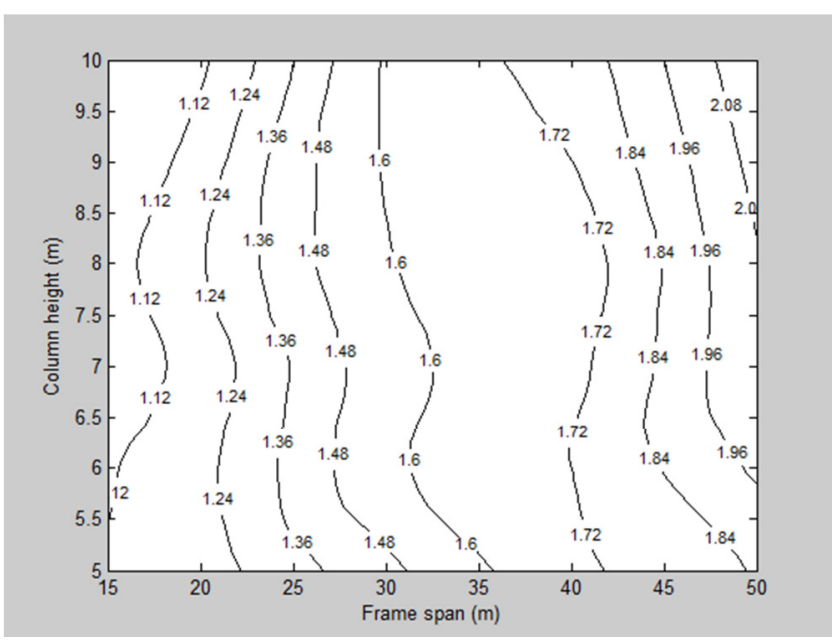

Fig. 14 Contour of DO4/DO1 using Haunch C

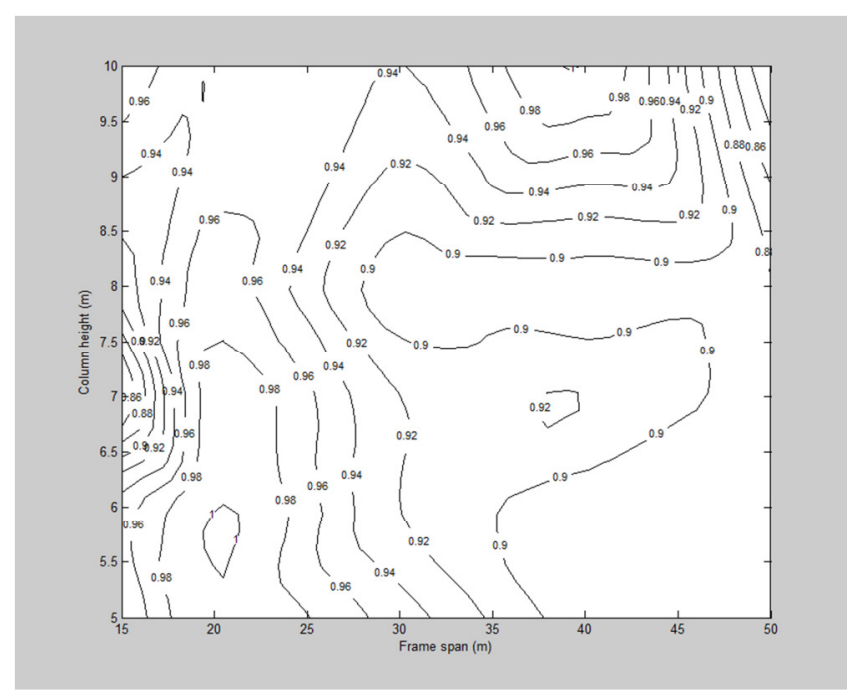

Fig. 15 Contour of Haunch C/ Haunch A for DO3 
Table 1 Deflection limits for steel portal frames

\begin{tabular}{|c|c|c|c|c|}
\hline & \multicolumn{2}{|c|}{ SCI recommendations [4] } & \multicolumn{2}{c|}{ Industry suggestions } \\
\cline { 2 - 5 } & $\begin{array}{c}\text { Absolute } \\
\text { deflection }\end{array}$ & $\begin{array}{c}\text { Differential } \\
\text { deflection } \\
\text { relative to } \\
\text { adjacent frame }\end{array}$ & $\begin{array}{c}\text { Absolute } \\
\text { deflection }\end{array}$ & $\begin{array}{c}\text { Differential } \\
\text { deflection } \\
\text { relative to } \\
\text { adjacent frame }\end{array}$ \\
\hline $\begin{array}{c}\text { Lateral deflection } \\
\text { at eaves }\end{array}$ & $\leq \frac{\mathrm{h}_{\mathrm{f}}}{100}$ & $\leq \frac{\mathrm{b}_{\mathrm{f}}}{200}$ & $\leq \frac{\mathrm{h}_{\mathrm{f}}}{100}$ & $\leq \frac{\mathrm{h}_{\mathrm{f}}}{150}$ \\
\hline $\begin{array}{c}\text { Vertical deflection } \\
\text { at apex }\end{array}$ & - & $\begin{array}{c}\mathrm{b}_{\mathrm{f}} \\
\text { and } \\
\sqrt{\mathrm{b}_{\mathrm{f}}{ }^{2}+\mathrm{s}_{\mathrm{f}}{ }^{2}} / 125\end{array}$ & - & $\leq \frac{\mathrm{L}}{200}$ \\
\hline
\end{tabular}

Table 2 Deflection limits for Reference Frame

\begin{tabular}{|c|c|c|c|c|}
\hline \multirow{2}{*}{} & \multicolumn{2}{|c|}{ SCI recommendations [4] } & \multicolumn{2}{c|}{ Industry suggestions } \\
\cline { 2 - 5 } & $\begin{array}{c}\text { Absolute } \\
\text { deflection }\end{array}$ & $\begin{array}{c}\text { Differential } \\
\text { deflection } \\
\text { relative to } \\
\text { adjacent frame }\end{array}$ & $\begin{array}{c}\text { Absolute } \\
\text { deflection }\end{array}$ & $\begin{array}{c}\text { Differential } \\
\text { deflection } \\
\text { relative to } \\
\text { adjacent frame }\end{array}$ \\
\hline $\begin{array}{c}\text { Lateral deflection } \\
\text { at eaves }\end{array}$ & $\leq 70 \mathrm{~mm}$ & $\leq 30 \mathrm{~mm}$ & $\leq 70 \mathrm{~mm}$ & $\leq 47 \mathrm{~mm}$ \\
\hline $\begin{array}{c}\text { Vertical deflection } \\
\text { at apex }\end{array}$ & - & $\begin{array}{c}\leq 60 \mathrm{~mm} \\
\text { and } \\
\leq 130 \mathrm{~mm}\end{array}$ & - & $\leq 150 \mathrm{~mm}$ \\
\hline
\end{tabular}

Table 3 Properties of steel sections used for Reference Frame

\begin{tabular}{|c|c|c|c|c|c|c|}
\hline Section & $\begin{array}{c}\mathrm{f}_{\mathrm{y}} \\
\left(\mathrm{N} / \mathrm{mm}^{2}\right)\end{array}$ & $\begin{array}{c}\mathrm{A} \\
\left(\mathrm{cm}^{2}\right)\end{array}$ & $\begin{array}{c}\mathrm{I}_{\mathrm{x}} \\
\left(\mathrm{cm}^{4}\right)\end{array}$ & $\begin{array}{c}\mathrm{Z}_{\mathrm{x}} \\
\left(\mathrm{cm}^{3}\right)\end{array}$ & $\begin{array}{c}\mathrm{S}_{\mathrm{x}} \\
\left(\mathrm{cm}^{3}\right)\end{array}$ & $\begin{array}{c}\mathrm{M}_{\mathrm{cx}} \\
(\mathrm{kNm})\end{array}$ \\
\hline $510 \times 229 \times 101$ UB & 265 & 129 & $7.57 \times 10^{4}$ & 2290 & 2610 & 692 \\
\hline $457 \times 191 \times 67$ UB & 275 & 85.5 & $2.94 \times 10^{4}$ & 1300 & 1470 & 649 \\
\hline
\end{tabular}

Table 4 Deflections of Reference Frame compared to serviceability limits

\begin{tabular}{|c|c|l|c|c|}
\hline & \multicolumn{2}{|c|}{ SCI recommendations } & \multicolumn{2}{c|}{ Industry suggestions } \\
\cline { 2 - 5 } & $\begin{array}{c}\text { Absolute } \\
\text { deflection }\end{array}$ & $\begin{array}{l}\text { Differential } \\
\text { deflection } \\
\text { relative to } \\
\text { adjacent frame }\end{array}$ & $\begin{array}{c}\text { Absolute } \\
\text { deflection }\end{array}$ & $\begin{array}{c}\text { Differential } \\
\text { deflection } \\
\text { relative to } \\
\text { adjacent frame }\end{array}$ \\
\hline $\begin{array}{c}\text { Lateral deflection } \\
\text { at eaves }\end{array}$ & $29.2 \mathrm{~mm}$ & $9.3 \mathrm{~mm}$ & $29.2 \mathrm{~mm}$ & $9.3 \mathrm{~mm}$ \\
\hline $\begin{array}{c}\text { Vertical deflection } \\
\text { at apex }\end{array}$ & - & $99.0 \mathrm{~mm}^{\mathrm{a}}$ & - & $99.0 \mathrm{~mm}$ \\
\hline
\end{tabular}

${ }^{\mathrm{a}}$ Unsatisfactory. 
Table 5 Validation of RC-NGA

\begin{tabular}{|c|c|c|c|c|c|}
\hline Approach & $\begin{array}{c}\text { Column sections } \\
(\mathrm{UB})\end{array}$ & $\begin{array}{c}\text { Rafter sections } \\
(\mathrm{UB})\end{array}$ & $\begin{array}{c}\text { Depth of } \\
\text { haunch }(\mathrm{m})\end{array}$ & $\begin{array}{c}\text { Length of } \\
\text { haunch }(\mathrm{m})\end{array}$ & $\begin{array}{c}\text { Total weight } \\
\left(\mathrm{kg} / \mathrm{m}^{2}\right)\end{array}$ \\
\hline Issa and Mohammad (2010) & $457 \times 152 \times 52$ & $406 \times 140 \times 46$ & 0.11 & 2.45 & 12.73 \\
\hline RC-NGA $^{\mathrm{a}}$ & $457 \times 152 \times 52$ & $356 \times 127 \times 33$ & 0.49 & 3.60 & 10.80 \\
\hline RC-NGA $^{\mathrm{b}}$ (elastic) & $406 \times 140 \times 46$ & $305 \times 102 \times 25$ & 0.30 & 1.25 & 7.80 \\
\hline RC-NGA $^{\text {b }}$ (plastic) & $305 \times 102 \times 25$ & $254 \times 102 \times 22$ & 0.30 & 6.10 \\
\hline
\end{tabular}

${ }^{\mathrm{a}}$ Deflection limits of Issa and Mohammad adopted [6]

${ }^{\mathrm{b}}$ Ultimate limit state design only

Table 6 Reference Frame sized using optimum plastic design

\begin{tabular}{|c|c|c|c|c|c|c|c|}
\hline \multirow[t]{2}{*}{ Haunch } & \multicolumn{2}{|c|}{ Haunch sizes } & \multirow{2}{*}{$\begin{array}{l}\text { Column section } \\
\text { (UB) }\end{array}$} & \multirow{2}{*}{$\begin{array}{c}\text { Rafter } \\
\text { section (UB) }\end{array}$} & \multirow[t]{2}{*}{$\mathrm{g}_{5}$} & \multirow{2}{*}{$\begin{array}{l}\text { Frame weight } \\
\qquad\left(\mathrm{kg} / \mathrm{m}^{2}\right)\end{array}$} & \multirow[t]{2}{*}{$\mathrm{FEs}^{\mathrm{a}}$} \\
\hline & $\mathrm{L}_{\mathrm{h}} / \mathrm{L}$ & $\mathrm{D}_{\mathrm{h}} / \mathrm{D}_{\mathrm{h} 0}$ & & & & & \\
\hline A & 0.10 & 1.0 & $510 x 229 x 101$ & $457 \times 191 \times 67$ & -0.04 & 20.21 & 8600 \\
\hline B & 0.095 & 1.0 & $510 \times 229 \times 101$ & $457 \times 191 \times 67$ & -0.02 & 20.13 & 9100 \\
\hline $\mathrm{C}$ & 0.13 & 0.96 & $610 \times 229 \times 101$ & $457 \times 152 \times 60$ & 0 & 19.21 & 9200 \\
\hline
\end{tabular}

${ }^{\mathrm{a}}$ Mean value for five runs all of which converged.

Table 7 Reference Frame sized using optimal elastic design

\begin{tabular}{|c|c|c|c|c|c|c|c|}
\hline \multirow[t]{2}{*}{ Haunch } & \multicolumn{2}{|c|}{ Haunch sizes } & \multirow{2}{*}{$\begin{array}{c}\text { Column } \\
\text { section (UB) }\end{array}$} & \multirow{2}{*}{$\begin{array}{l}\text { Rafter section } \\
\text { (UB) }\end{array}$} & \multirow[t]{2}{*}{ Active constraint ${ }^{\mathrm{a}}$} & \multirow{2}{*}{$\begin{array}{c}\text { Frame weight } \\
\left(\mathrm{kg} / \mathrm{m}^{2}\right)\end{array}$} & \multirow[t]{2}{*}{$\mathrm{FEs}^{\mathrm{b}}$} \\
\hline & $\mathrm{L}_{\mathrm{h}} / \mathrm{L}$ & $\mathrm{D}_{\mathrm{h}} / \mathrm{D}_{\mathrm{h} 0}$ & & & & & \\
\hline A & 0.10 & 1.00 & $610 \times 229 \times 113$ & $457 \times 191 \times 74$ & $\begin{array}{c}\mathrm{g}_{4 \mathrm{E}}=-0.02 \\
(\text { on column })\end{array}$ & 22.43 & 8500 \\
\hline B & 0.12 & 1.00 & $610 \times 229 \times 125$ & $457 \times 191 \times 67$ & $\begin{array}{c}\mathrm{g}_{4 \mathrm{E}}=-0.02 \\
(\text { on column })\end{array}$ & 22.30 & 8800 \\
\hline $\mathrm{C}$ & 0.14 & 1.05 & $610 \times 229 \times 125$ & $457 \times 152 \times 60$ & $\begin{array}{c}\mathrm{g}_{4 \mathrm{E}}=-0.01 \\
\text { (at haunch end) }\end{array}$ & 21.12 & 9200 \\
\hline
\end{tabular}

${ }^{\mathrm{a}}$ Apparent slack is due to discrete decision variables. ${ }^{\mathrm{b}}$ Mean value for five runs all of which converged.

Table 8 Reference Frame sized using optimal elastic SCI serviceability deflection limit design

\begin{tabular}{|c|c|c|c|c|c|c|c|}
\hline \multirow{2}{*}{ Haunch } & \multicolumn{2}{|c|}{ Haunch sizes } & \multirow{2}{*}{$\begin{array}{c}\text { Column } \\
\text { section }(\mathrm{UB})\end{array}$} & \multirow{2}{*}{$\begin{array}{c}\text { Rafter section } \\
(\mathrm{UB})\end{array}$} & \multicolumn{2}{|c|}{ Maximum constraint factors } & \multirow{2}{*}{$\begin{array}{c}\text { Frame weight } \\
\left(\mathrm{kg} / \mathrm{m}^{2}\right)\end{array}$} \\
& $\mathrm{L}_{\mathrm{h}} / \mathrm{L}$ & $\mathrm{D}_{\mathrm{h}} / \mathrm{D}_{\mathrm{h} 0}$ & & & $\mathrm{ULS}$ & $\mathrm{SLS}$ & \\
\hline $\mathrm{A}$ & 0.10 & 1.00 & $686 \times 254 \times 125$ & $533 \times 210 \times 82$ & $\begin{array}{c}\mathrm{g}_{4 \mathrm{E}}=-0.20 \\
(\text { on column })\end{array}$ & $\mathrm{g}_{7}=-0.04$ & 24.84 \\
\hline $\mathrm{B}$ & 0.14 & 1.00 & $610 \times 229 \times 113$ & $533 \times 210 \times 82$ & $\begin{array}{c}\mathrm{g}_{4 \mathrm{E}}=-0.03 \\
(\text { on column })\end{array}$ & $\mathrm{g}_{7}=-0.01$ & 24.45 \\
\hline $\mathrm{C}$ & 0.17 & 1.32 & $686 \times 254 \times 125$ & $457 \times 191 \times 74$ & $\begin{array}{c}\mathrm{g}_{4 \mathrm{E}}=-0.15 \\
(\text { on column })\end{array}$ & $\mathrm{g}_{7}=0$ & 24.34 \\
\hline
\end{tabular}


